\title{
SOCIOLOGIA DO DIREITO E TEORIA DOS SISTEMAS: UMA ENTREVISTA COM O PROFESSOR ALFONS BORA*
}

Entrevistadores e tradutores:

Gabriel Ferreira da Fonseca ${ }^{1}$, Lucas Fucci Amato ${ }^{2}$, Marco Antonio Loschiavo Leme de Barros ${ }^{3}$, Edvaldo de Aguiar Portela Moita ${ }^{4}$, Henrique Carvalho ${ }^{5}$ Artur Stamford da Silva ${ }^{6}$

Nos dias 26 e 27 de setembro de 2019, o Professor Alfons Bora (Faculdade de Sociologia da Universidade de Bielefeld - Alemanha) esteve na Faculdade de Direito da Universidade de São Paulo (USP) para apresentar duas palestras no Ciclo de Seminários Internacionais "Repensando Luhmann e a pesquisa sociojurídica: uma

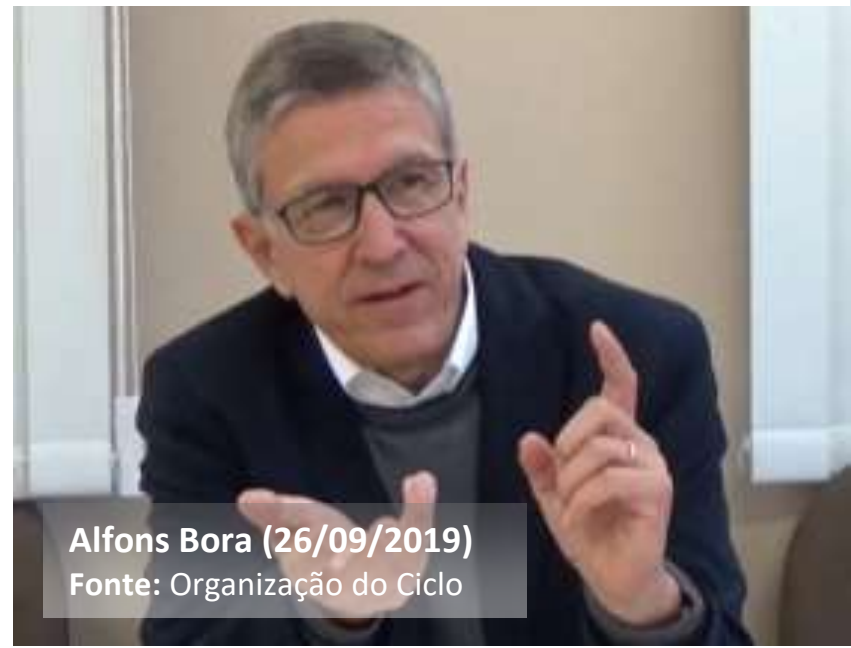
agenda empírica para a teoria dos sistemas sociais?" Os encontros foram coordenados pelo Professor Celso Fernandes Campilongo e seus ex-orientandos Gabriel Ferreira da Fonseca, Lucas Fucci Amato e Marco Antonio Loschiavo Leme de Barros. O objetivo do ciclo de seminários foi reunir pesquisadores, principalmente da área de Sociologia do

\footnotetext{
* Professor de Sociologia na Universidade de Bielefeld desde 1999. Dr. Phil., Sociólogo (M.A.), Advogado (Assessor jurídico).

${ }^{1}$ Professor de Direito no Centro Universitário de Salvador e Assistente de Gabinete no Tribunal de Contas do Estado da Bahia. Doutor em Direito pela Universidade de São Paulo, com períodos de pesquisa na Faculdade de Sociologia da Universidade de Bielefeld, sob a orientação do Professor Rafael Diniz Pucci e a coorientação do Professor Alfons Bora.

2 Professor Colaborador e pós-doutor em Direito pela Universidade de São Paulo.

${ }^{3}$ Professor Doutor da Faculdade de Direito da Universidade Presbiteriana Mackenzie.

${ }^{4}$ Doutorando em Sociologia na Universidade de Bielefeld e em Direito na Universidade de Brasília (cotutela), sob a orientação dos Professores Alfons Bora e Marcelo Neves.

${ }^{5}$ Doutor em Sociologia pela Universidade de Bielefeld, sob a orientação do Professor Alfons Bora.

${ }^{6}$ Professor Titular de Direito da Universidade Federal de Pernambuco. Pesquisador 1D, pelo CNPq.
} 
Direito, e promover reflexões sobre o potencial de enriquecimento mútuo entre teoria dos sistemas e pesquisa empírica ${ }^{7}$.

No final da tarde de 26 de setembro, antes da sua primeira palestra, o Professor Alfons Bora nos concedeu uma entrevista em inglês, na sala de reuniões do Departamento de Filosofia e Teoria Geral do Direito, no Largo São Francisco (Faculdade de Direito da USP). Algumas perguntas foram enviadas antecipadamente para ele, mas, em geral, as questões foram reformuladas durante a conversa, que foi integralmente filmada.

Durante a entrevista de 1 hora e 20 minutos, às vezes interrompida pelos sons e barulhos do centro de São Paulo, o Professor Alfons Bora respondeu às perguntas com densidade teórica e bom humor. Nas respostas, o entrevistado abordou, por exemplo, aspectos biográficos relacionados à sua formação acadêmica e trajetória profissional, como o contexto histórico e pessoal em que desenvolveu seu interesse pela Sociologia e, posteriormente, pela teoria dos sistemas. Além disso, houve oportunidades para o Professor abordar alguns tópicos centrais de sua agenda de pesquisa nessas áreas, como a adoção dos conceitos de "discurso" e "responsividade", o foco em sistemas organizacionais e o uso da distinção inclusão/exclusão.

O resultado da conversa foi o texto a seguir, que resume algumas das principais discussões desenvolvidas nas últimas décadas no campo da Sociologia do Direito e, principalmente, da teoria dos sistemas. Com a experiência de quem dedicou a maior parte de sua vida a essas questões, o Professor Alfons Bora enfrenta e repensa distinções clássicas da área, como aquelas entre normas e fatos; ciência e prática; teorias e métodos.

\footnotetext{
${ }^{7} \mathrm{O}$ ciclo de seminários contou com o apoio da Fundação de Amparo à Pesquisa do Estado de São Paulo (FAPESP) e do Programa de Excelência Acadêmica da Coordenação de Aperfeiçoamento de Pessoal de Nível Superior (PROEX/CAPES), auxílio este dirigido ao Programa de Pós-Graduação em Direito da Faculdade de Direito da USP.
} 


\section{ASPECTOS BIOGRÁFICOS}

Gabriel Fonseca - Professor Alfons Bora, muito obrigado por aceitar o nosso convite para falar sobre sua carreira, teoria dos sistemas, Sociologia do Direito, pesquisa empírica, estudos sociolinguísticos, entre outros temas. Queremos começar perguntando sobre seu interesse pela teoria dos sistemas e pela Sociologia do Direito. Como você se interessou por essas abordagens? Existem aspectos biográficos relacionados a tais interesses?

Alfons Bora - Bem, na verdade, são duas perguntas: uma sobre a Sociologia do Direito e a outra sobre a teoria dos sistemas em particular. Eu gostaria de começar com a Sociologia do Direito, porque esse foi o primeiro ponto em que entrei em contato com a Sociologia. Em meados da década de 1970... Talvez seja útil dizer algumas palavras sobre o contexto histórico. Essa era uma época em que a cientificização social da teoria do direito e da educação jurídica era muito forte. Todos estavam interessados na Sociologia como uma ciência geral que explicaria tudo, particularmente na teoria do direito e na educação jurídica. Então, todo mundo era crítico e queria criticar o direito, e é por isso que a Sociologia era extremamente atraente naqueles dias.

O segundo ponto foi que em Freiburg, onde eu estudava, havia um sociólogo que era - ou ainda é - um professor realmente carismático, Günter Dux. Como eu diria hoje, ele é mais um antropólogo social - não tanto um sociólogo -, mas foi ele quem de alguma forma me trouxe à Sociologia, e esse foi o meu primeiro passo. Estudei Direito e pensei que aquilo não deveria ser tudo o que eu queria saber. Queria saber mais e algo diferente. Então, comecei a estudar Sociologia como um segundo assunto. Também poderia ter sido História ou algo assim, mas, de todo modo, algo diferente da doutrina e da dogmática jurídica, que parecia muito antiquada naqueles dias. Então, eu comecei a estudar Sociologia.

A segunda pergunta - como entrei em contato com a teoria dos sistemas? - isso aconteceu depois, é claro. Primeiro, com Günter Dux, estávamos muito interessados na teoria crítica e no seu aprimoramento e desenvolvimento. Por isso, lemos muito de Jürgen 
Habermas. A Teoria da Ação Comunicativa, publicada em 1981, era a nossa Bíblia. Lemos tudo e tentamos criticá-la, porque Günter Dux, nosso professor, meu orientador de doutorado, queria criticar Habermas. Essa era a teoria com a qual estávamos lidando e nosso ponto de referência, se você preferir.

Então, em 1984, li por acaso Luhmann e, é claro, já havia lido muitas coisas antes, mas, naquele momento, comecei com o livro Sistemas Sociais. Ele foi publicado em 1984, então eu li exatamente naquele ano. Esse foi o período em que fiquei completamente fascinado e pensei "bem, isso seria Sociologia, não Habermas; Habermas é Filosofia Social!" Então, eu tive uma ideia do que uma boa Sociologia poderia ser ou seria. Portanto, esse foi meu primeiro contato real com Luhmann e, desde então, tentei, de alguma maneira, compreender essa teoria e a conexão com uma Sociologia do Direito. Obviamente, porque sou advogado e, mais do que antes, hoje diria que também sou um advogado. Sou sociólogo, mas também advogado. Por isso, estou interessado nesse campo em particular.

Gabriel Fonseca - Como você chegou em Bielefeld, como foi o seu acesso à Universidade de Bielefeld?

Alfons Bora - Essa é uma longa história. Primeiro de tudo, eu estava em Freiburg. Havia apenas um lugar onde, como sociólogo, você podia trabalhar por dinheiro: esse era o Instituto Max Planck de Direito Penal Estrangeiro e Internacional. Eles tinham um grupo de pesquisa em Criminologia e este era um lugar onde os sociólogos eram necessários como assistentes de pesquisa empírica. Eles tinham que fazer todas as entregas para os advogados. Os advogados faziam as perguntas e os sociólogos tinham que oferecer o conteúdo empírico. Foi aí que comecei a desenvolver pesquisas empíricas sobre aborto, falência, processo criminal etc. 
Quando o tempo acabou e eu não consegui um novo emprego, fiquei um pouco desamparado. Fiz meu segundo exame estatal em Direito naquele momento e depois trabalhei na minha tese de doutorado em Sociologia. Então, a pergunta era o que eu poderia fazer, de onde eu poderia conseguir algum dinheiro?

E, então, havia um anúncio em um grande jornal, Die Zeit: uma posição era anunciada no Centro de Pesquisa em Ciências Sociais de Berlim (Wissenschaftszentrum Berlin für Sozialforschung, WZB), em um grupo de pesquisa sobre regulamentação ambiental. Estudamos procedimentos, meios alternativos de resolução de conflitos, mediação e algo chamado Avaliação Participativa de Tecnologia, que era o assunto principal. Nesse ponto, entrei em contato com procedimentos participativos e comecei a sugerir meus próprios projetos, um pouco diferente do que estava acontecendo em Berlim na época. Esse foi o tema da minha tese de habilitação.

Quando terminei a habilitação, a próxima chance de sorte surgiu naquele momento em Bielefeld. Havia uma vaga, uma cadeira de professor para Avaliação de Tecnologia. Eu me candidatei e consegui. Desde então, estou em Bielefeld.

É uma biografia um pouco chata. Foi tudo uma questão de sorte, chances e contingência. Foi mais ou menos contingência, além do meu interesse em teoria e na combinação de teoria e pesquisa empírica em um campo que você poderia descrever mais ou menos como Sociologia do Direito, Sociologia da Regulação, Teoria Sociológica do Direito. Não tenho história com Bielefeld que remonte à época dos meus estudos, como alguns de vocês têm.

\section{TEORIA DOS SISTEMAS NO BRASIL E NA ALEMANHA}

Marco Barros - No Brasil, geralmente observamos que a teoria dos sistemas tem uma considerável inserção nas Faculdades de Direito. Por exemplo, podemos tomar como referências as obras dos professores Marcelo Neves, Celso Fernandes Campilongo, Willis Santiago Guerra Filho, Artur Stamford da Silva, entre outros. Contudo, geralmente não vemos esse tipo de discussão nos departamentos de Sociologia. Por exemplo, na 
Universidade de São Paulo, há poucos docentes que estudam teoria dos sistemas no Departamento de Sociologia. Então, eu gostaria de perguntar se você observa a mesma situação na Alemanha, ou na Europa em geral. Qual a sua perspectiva em relação a isso?

Alfons Bora - Não tenho muita certeza sobre esse ponto. Não tenho dados estatísticos válidos, mas acho que não estou errado em dizer que a situação da Sociologia em geral é muito semelhante à que você descreveu no Brasil. A teoria dos sistemas é um fenômeno marginal, muito marginal, uma parte microscópica da Sociologia sobre a qual outros sociólogos olham com alguma suspeita e de uma distância muito grande, pois é difícil, não é fácil entrar em contato com a linguagem, é um pouco estranha e todas essas coisas. Já é o bastante sobre a Sociologia.

Agora eu poderia estender a sua pergunta à relação entre Sociologia e muitos outros campos: como é isso na Economia, como é na Ciência Política, como é na História...? A Sociologia do Direito é apenas um dos muitos campos possíveis em que você pode fazer sua pergunta.

Entretanto, voltando à Sociologia do Direito, minha impressão é de que, na Alemanha, o interesse geral na teoria dos sistemas talvez seja um pouco mais intenso nos departamentos de Direito do que nos departamentos de Sociologia. No entanto, eu digo isso com muita relutância, porque não sei como medir. Como medimos o interesse? Teríamos que perguntar às pessoas, contar e fazer estatísticas. Ou, por exemplo, poderíamos ir aos planos de estudos e examinar quais são as questões de ensino ou pesquisa. Isso é um pouco difícil, é o que eu quero dizer.

Minha impressão é de que sim: conheço muitos advogados, professores de Direito, colegas de grandes departamentos da área de Direito, que estão interessados em teoria dos sistemas. Isso é maravilhoso porque me dá alguma ressonância, eu recebo respostas e são pessoas com quem eu posso argumentar e discutir, mas não tenho certeza sobre o ponto em geral. Intuitivamente, eu diria que sim, talvez seja muito parecido. Talvez. 


\section{SOCIOLOGIA E RESPONSIVIDADE}

Gabriel Fonseca - Você começou a falar sobre teoria crítica e eu tenho uma pergunta sobre essa distinção entre pesquisas sociojurídicas normativas (ou críticas) e descritivas (ou analíticas). Como você vê essa distinção? Você acha que a ideia de responsividade que você tem desenvolvido pode nos ajudar a repensar essas duas perspectivas sobre a Sociologia do Direito e a teoria dos sistemas? Ou são questões diferentes?

Alfons Bora - Se você voltar a Max Weber, acho que encontrará as respostas mais importantes para essa pergunta sobre a natureza da distinção entre ciências normativas e ciências empíricas. Embora o próprio Weber tenha tentado encontrar uma posição intermediária em suas obras metodológicas, mas, resumindo a longa história, eu diria que, desde Weber, não foram ditas muitas coisas importantes sobre o assunto. Quero dizer, existe uma profunda lacuna entre argumentos normativos (sollen, dever) e observações empíricas (explicações, relações causais, o que você quiser) que não é nada que você possa preencher facilmente.

O que tornou a teoria crítica tão promissora e atraente nas décadas de 1960 e 1970 foi a ideia que, desde Adorno e Horkheimer, o início da Escola de Frankfurt promoveu: a ideia de que é possível preencher a lacuna, criar argumentos normativos sobre o conhecimento empírico. Esses foram os estudos sobre autoritarismo e os primeiros trabalhos da teoria crítica. Todos eles se basearam nessa tentativa de, de alguma forma, chegar a uma justificação empírica, nesse sentido, de afirmações "normativas" (sentenças sobre a boa sociedade, o que torna nossa vida boa e valiosa). Naturalmente, isso é enormemente atraente para os jovens, que querem ser críticos.

Essa foi a razão pela qual estávamos interessados em Habermas. Ele tentou reorganizar a teoria porque alguns elementos centrais do pensamento marxista estavam em colapso durante as décadas de 1930 e 1940, especialmente a consciência de classe. Coisas assim não eram mais viáveis. Você não podia reivindicar coisas como Marx e, mais tarde, Lenin. 
Então, essa foi a tentativa de Habermas de alguma forma modernizar e reconstruir a teoria crítica com base no conceito de comunicação e que a tornou realmente atraente e, em determinado momento - foi principalmente na minha tese - cheguei à conclusão de que a solução de Habermas não funciona. Ele tenta reorganizar os argumentos sociológicos nas partes sobre "Parsons encontra Durkheim" na Teoria da Ação Comunicativa e o faz de uma maneira muito eclética, uma espécie de bricolagem. Ele apenas reúne as partes teóricas para ajustá-las à sua teoria da ação comunicativa. Isso não é muito convincente. Para mim, não era Sociologia, no final das contas. Era Filosofia Social. Eu estou muito com ele, com a teoria do discurso, quando se trata de argumentos normativos. Essa é uma maneira forte de argumentar normativamente, mas a base, como eu penso, é bastante fraca.

Isso já é o suficiente sobre a relação geral entre normas e fatos.

A "responsividade" está de alguma forma relacionada a isso, mas é mais abstrata e um pouco mais por trás disso. O conceito está relacionado a teorias reflexivas na Sociologia e à maneira como elas se relacionam com o ambiente social da ciência. Este é um desenvolvimento mais recente na Sociologia da Ciência e na teoria reflexiva da ciência.

Um ex-aluno meu, David Kaldewey - que agora é professor em Bonn -, tenta argumentar que a teoria dos sistemas, de certa forma, exagera demais o momento do fechamento, da autonomia, e que Luhmann, de certa forma, negligenciou o fato de que a ciência, desde Aristóteles, sempre refletiu sobre esse ambiente, que sempre existiram discursos do que você poderia chamar de prática. Essa é uma compreensão muito difícil e específica da prática, porque é um discurso dentro da sociedade, faz parte da sociedade. Ela tem uma função limitadora contra a autonomia exagerada. Portanto, é aqui que a responsividade pode estar localizada, afinal.

Há uma conexão frouxa com essa antiga distinção binária entre "fatos" e "normas", "ser" e "dever-ser", "ciência empírica" e "ciência normativa", mas acho que a ideia vai um 
pouco mais longe. É fortemente baseada na teoria dos sistemas e na ciência nãonormativa. Embora eu confesse que, em relação a Gunther Teubner, por exemplo, ele tenta restabelecer muitos pensamentos da teoria crítica e acredito que ele deveria ser mais cauteloso em muitos aspectos. O que tento com essa ideia de responsividade é de alguma forma segui-lo, mas apenas até certo ponto, em que digo: “Não seja tão normativo".

Edvaldo Moita - Posso aproveitar esse ponto? É que eu estava em uma conferência lá em Bielefeld, e um professor de Sociologia disse: "qualquer Sociologia normativa é uma Sociologia ruim". Você concorda com isso?

Alfons Bora - A frase é muito forte, muito curta. Não é realmente reflexiva. Eu não concordaria com ele nessa formulação. A Sociologia, é claro, não é uma ciência normativa. É uma ciência empírica. Não há razão para discutir sobre isso. Contudo, a responsividade e a reflexividade (essa ideia de prática como parte do mecanismo interno da ciência) vão além dessa simples distinção entre fatos e normas. É um pouco mais complicado, como eu diria. Portanto, pode ser realmente atraente. Eu gosto muito de responsividade.

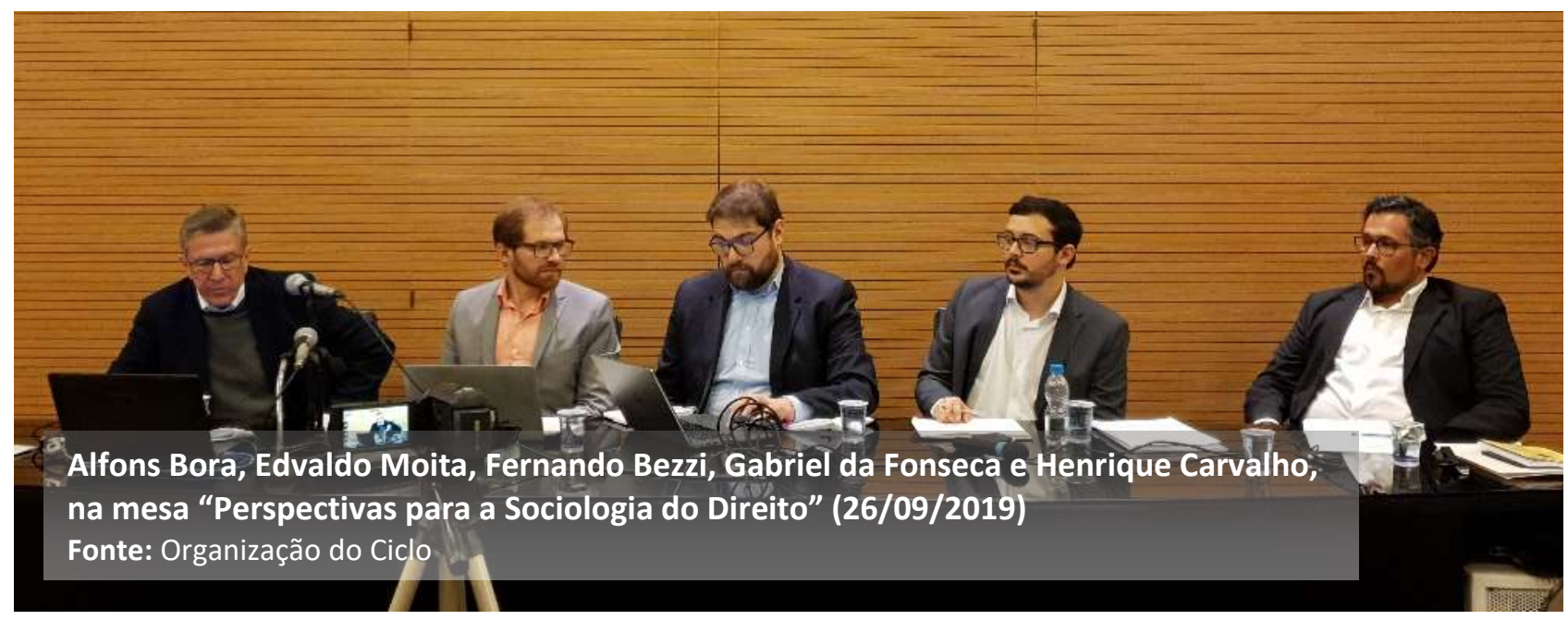




\section{PROBLEMAS DE PESQUISA E METODOLOGIAS}

Gabriel Fonseca - Podemos ir agora para outro tópico que você tem desenvolvido. Você tem muitos trabalhos baseados em estudos sociolinguísticos. Como você articula teoria dos sistemas e pesquisa empírica? A abordagem sociolinguística pode realmente nos ajudar com essa tarefa? Quais outras abordagens podem ser úteis para essa vinculação entre pesquisa empírica e teoria dos sistemas?

Alfons Bora - Deixe-me começar com a Sociolinguística e dar uma resposta muito curta e bastante relutante. A Sociolinguística pode ajudar a conduzir estudos empíricos, mas apenas em um sentido muito específico, não com relação a uma certa teoria. Essa abordagem está relacionada a assuntos, campos e perguntas.

Agora, vamos começar com o início da sua pergunta. Em geral, eu argumentaria que não há conexão necessária entre teoria e métodos empíricos. Não, não existe. Depende de perguntas. Eu diria que você precisa pensar em métodos quando souber quais perguntas vêm da sua teoria e que podem ser muito diferentes e vários tipos de perguntas. Portanto, a teoria não aciona ou fixa, de maneira alguma, métodos. Os métodos são abertos, nesse sentido de que não existem relações necessárias. Eu estaria interessado em ouvir argumentos, se vocês pensam que é o contrário. Eu não consigo ver isso.

Essa é a observação geral e agora, no que diz respeito às metodologias e sua relação com tipos específicos de perguntas, acho que pode nos ajudar uma distinção entre dois tipos de perguntas.

Perguntas que visam números, se você quiser saber quantos casos e como são as relações entre esses casos e outro caso... Em outras palavras, generalizações estatísticas. Você pode tirar conclusões de $n$ casos para $n$ mais $x$ casos. Essa é uma metodologia, um paradigma analítico empírico, muito importante, e é muito poderosa. Eu não quero atacar esses tipos de métodos. Há uma luta muito infrutífera entre diferentes metodologias na Sociologia e isso é completamente inútil, eu argumentaria. Você deve julgar ou decidir sobre as metodologias dependendo do que deseja saber. Considerando o primeiro tipo de 
perguntas - questões de números, frequências -, quantos filhos teremos em dez anos, para que possamos saber quantos jardins de infância precisamos construir? Isso é muito importante, é uma pergunta real, é uma questão prática. Também é teoricamente interessante se você estiver no campo da Ciência Política, no planejamento político ou em assuntos governamentais.

O segundo tipo de questão está relacionado a casos e a explicações causais, mais fortemente do que o primeiro. A estatística, o paradigma analítico empírico, também afirma fornecer explicações causais, mas isso é um pouco difícil, porque causalidade e correlação não necessariamente andam juntas. As correlações não dizem nada sobre causalidades. De onde obtemos as causalidades? Podemos tomar a Medicina como exemplo. Explicações causais, tradicionalmente - nem sempre, mas tradicionalmente -, vêm das pesquisas clínicas. Patologia: você abre um corpo, olha para ele e tenta entender o que encontra. Você vê: "Oh! Existe esse pequeno organismo e aqui tenho os sintomas, eles podem estar relacionados." Agora, eu tento entender os mecanismos.

Esse tipo de perspectiva clínica tenta reconstruir os mecanismos "lógicos" internos de um único caso, a fim de entender todos os casos semelhantes. Depois de encontrar a bactéria, você pode afirmar de maneira generalizada - generalização estrutural - que todos os casos semelhantes serão explicados da mesma maneira. Então, essa é uma perspectiva muito diferente, um tipo muito diferente de pergunta, e aí você encontra métodos clínicos, métodos de casos, métodos reconstrutivos...

Em analogia com a Medicina, eu diria, o mesmo vale para as Ciências Sociais em geral. Também temos perspectivas clínicas, estudos de caso. Entendidos corretamente, os estudos de caso têm como objetivo produzir relações causais, explicações, que fornecem um certo tipo de generalização, generalização estrutural, o que significa que todos os casos que mostram estruturas semelhantes encontrarão as mesmas relações causais. Esta é uma pergunta muito diferente da primeira. Ambos os tipos de perguntas podem ser conectados e relacionados a qualquer tipo de teoria. Não há relação entre teorias e métodos. 
E, finalmente, voltando à segunda parte da sua pergunta, a Sociolinguística geralmente pode ser usada, e eu tenho feito isso durante muito tempo da minha vida, junto com Heiko Hausendorf, principalmente para estudos de caso, para estudos de comunicação, em particular. Portanto, ela é apta para um tipo de teoria que se baseia na noção de comunicação, em um entendimento específico de comunicação, mas que visa uma perspectiva clínica. Não sei se isso está claro. Discutirei amanhã na minha apresentação ["Observação e prática: Exemplos e perspectivas futuras da teoria sociológica dos sistemas em pesquisas sociojurídicas"].

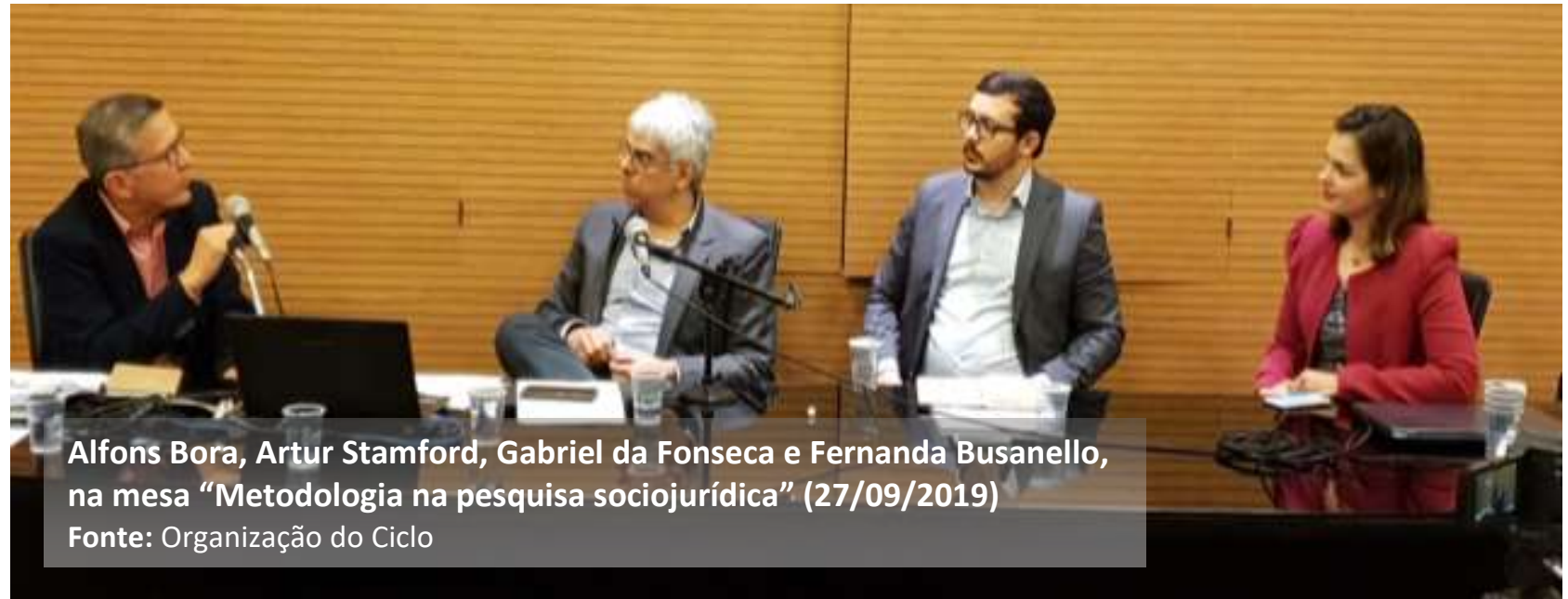

\section{TEORIA DOS SISTEMAS E PESQUISA EMPÍRICA}

Lucas Amato - Minha pergunta é sobre o uso da teoria dos sistemas para realizar pesquisas empíricas: se às vezes ela é supérflua, se alguns fenômenos podem ser mais bem descritos por outras teorias... Como você vê essa maneira não dogmática de estudar os fenômenos?

Alfons Bora - Bem, primeiro, em minha própria pesquisa, encontrei perguntas que não tinham sido respondidas suficientemente ou apenas pela teoria dos sistemas. Fenômenos relacionados principalmente à diferenciação interna do que Luhmann descreveu como sistemas funcionais, organizações e interações. Suas sistemáticas e terminologias são 
bastante convincentes, eu diria, mas talvez ela possa ser desenvolvida um pouco mais quando você a usa em certos tipos de fenômenos.

No meu caso, este foi principalmente o fenômeno que mais tarde chamei de "discurso". Eu encontrei coisas no mundo que não se encaixavam perfeitamente na terminologia de Luhmann e minha conclusão não foi ignorar a teoria, mas sim tentar ver se ela oferece opções para de alguma forma integrar os fenômenos em uma descrição mais detalhada. Foi por isso que comecei a usar a noção de "posição social" na teoria com Heiko Hausendorf. Tiramos isso do campo da Sociolinguística, e eu mesmo de algum modo adotei o termo "discurso". No entanto, não é Foucault, não é Goffman, não é Habermas, é um entendimento teórico-sistêmico de certos tipos de fenômenos, que chamei de "discurso". David Kaldewey, que mencionei antes, fez uso dessa ideia em sua Sociologia da Ciência de uma maneira um pouco diferente, mas isso também seria um exemplo de como desenvolver ainda mais a teoria. Ponto um.

Ponto dois: o aspecto sobre o qual eu estava falando há alguns minutos. A relevância interna do ambiente. Você poderia argumentar que isso já está incorporado no padrão da teoria dos sistemas: na noção de heterorreferência, observação, distinção, coisas assim. Isso é verdade, é claro, mas, a esse respeito, Luhmann talvez não tenha ido longe o suficiente ou não tenha tido tempo para ir longe o suficiente. Fiquei impressionado com a ideia de prática de David Kaldewey como parte interna da ciência e com a ideia de que você poderia desenvolver a teoria dos sistemas de uma maneira que o mundo externo - o ambiente - tivesse uma palavra dentro do sistema. Isso é completamente heterodoxo, não faz parte do cânone oficial, mas acho interessante e produtivo. Aprendi muito com isso e certamente tentaria usá-lo mais. Portanto, esse é outro exemplo em que a teoria tem um alto potencial para desenvolvimentos futuros. O próprio Luhmann - isso não é um argumento, é apenas outra ótica - foi fortemente contra essa atitude, contra os clássicos (você os admira e acende velas: "não toque neles"). Ele sempre foi muito irônico e riu dessa atitude. 
Finalmente: descobertas que contradizem premissas teóricas. Não tenho certeza. Penso que

REPENSANDO LUHMANNEA PESQUISA SOCIOJURIDICA: UMA AGENDA EMPIRICA PARA A TEORIA DOS SISTEMAS você não pode falsear teorias. Você pode falsear hipóteses, sentenças, mas não teorias. Se uma teoria é realmente uma boa teoria, ou seja, é abrangente, complexa, válida de certa forma, de modo a cobrir os fenômenos, geralmente você não será capaz de falseá-la. Uma boa teoria universal é capaz de descrever o mundo. Parsons, até Foucault... Como você os falsearia? Não... Você pode tentar atacar sentenças singulares, reivindicações, reivindicações de validade. Algo muito antiquado. Alguém diz " $x$ " e você tenta encontrar "não, não é ' $x$ '". "Todos os cisnes são brancos ou pretos", e você tenta encontrar o primeiro azul e, depois de encontrá-lo, pode afirmar que a frase estava errada. No entanto, com teorias, isso é diferente. Acho que não encontrei um argumento para atacar a teoria dos sistemas até agora. Fenômenos em relação aos quais a teoria dos sistemas pode ser supérflua, falando francamente, surpreendentemente, não, eu não os encontrei.

Minha experiência pessoal sempre foi a de que a teoria dos sistemas é uma oferta muito rica, que me permite ver fenômenos ad libitum, sem qualquer limitação, de uma nova maneira. Ontem, conversamos sobre nossas pesquisas e contatos com outros colegas e fiz um breve relato sobre minha relação com Frankfurt, com o Max Planck Institute... Eles me convidaram para uma conferência sobre diversidade e nunca havia pensado em diversidade antes, então me sentei e, alguns meses depois, tinha um artigo bastante longo sobre diversidade de uma perspectiva sociológica e foi com a teoria dos sistemas. Não fui aos livros para aprender o que é diversidade, mas minha tarefa era descobrir o que esse 
tipo de teoria pensaria sobre um fenômeno como "diversidade". Foi esclarecedor para mim. Aprendi muito. Espero que outros também tenham aprendido, naturalmente, mas aprendi muito e esse é o aspecto dessa teoria que me faz, se posso confessar, feliz como cientista. É sempre surpreendente e leva você a pontos de vista completamente novos. Então, não a acho supérflua.

\section{TEORIA DOS SISTEMAS E ORGANIZAÇÕES}

Marco Barros - Minha pergunta é sobre a observação de sistemas organizacionais. Avalio que esse é um fator importante para pensarmos nas possibilidades de aplicação da pesquisa jurídica empírica. Você mencionou antes a ideia de estudos de caso... Então, gostaria de perguntar se você acha que o foco em sistemas organizacionais, como tribunais, bancos, empresas etc. é uma maneira promissora de conduzir uma pesquisa jurídica empírica baseada na teoria dos sistemas.

Alfons Bora - Eu concordo, pelo menos com muita frequência. Não em geral. Não há sentido em dizer que você deve sempre abordar as organizações, mas, sim, com muita frequência, e especialmente nos pontos em que há debates críticos sobre a teoria dos sistemas, em que as pessoas afirmam que "a teoria não explica isso e não vê isso...". Muitas vezes, percebo que eles não veem organizações. Esse é um dos problemas da teoria dos sistemas: todo mundo está falando sobre sistemas funcionais ("no direito não é possível..."; "a economia não pode fazer..."), e eu me treino para voltar um passo e perguntar: “O que é economia nesse caso? O que é o direito? É realmente o 'direito' ou é um tipo específico de sistema ou rede organizacional ou qualquer outra coisa (existem muitas variedades) que faz uso do direito dentre outras coisas?"

Por exemplo, alguns anos atrás, tivemos um debate sobre juridificação, Verrechtlichung, uma maravilhosa palavra alemã. Habermas fez uso dela: a juridificação da sociedade moderna. Depois percebi que eu não entendia o que aquilo significava, simplesmente não entendia. De onde eu sabia que a sociedade era juridificada? Quando falamos de sociedades que são funcionalmente diferenciadas e têm sistemas específicos 
operando universalmente, o direito é um sistema funcional da sociedade mundial. Como ele poderia "juridificar" a sociedade? Ele opera!

No entanto, eu pensei que eles tinham alguma razão quando falavam sobre juridificação. Não está errado, há algo sobre isso, há muitas esferas, muitos campos em nosso mundo, em nossa experiência, em que você pensa: "oh, há muito direito de uma maneira que não havia antes, então há algo mudando". Foi quando eu aprendi por mim mesmo que deveríamos falar melhor sobre organizações. As organizações podem ser juridificadas, e a teoria dos sistemas nos fornece os termos conceituais para explicar isso: programação múltipla, referências múltiplas e uma mudança de peso entre os diferentes programas. Isso é muito fácil.

Os tribunais produzem sentenças jurídicas, mas eles são programados juridicamente, economicamente, politicamente, você escolhe. A referência ao direito é sempre a número um, as outras referências ficam atrás dela. Obviamente, você precisa de dinheiro para pagar serviços de secretaria e dinheiro para comprar papéis e comprar computadores no tribunal, coisas assim. O dinheiro é importante para a programação da operação organizacional. Obviamente, você pode observar uma economicização quando, por exemplo, a economia torna-se mais importante do que o direito nos tribunais. Então, de repente, tudo se torna empírico, instrutivo, você sabe o que precisa procurar.

Portanto, sim, eu concordo, há uma certa fraqueza, não na teoria dos sistemas, mas em um foco generalizado nos sistemas funcionais. Muitas vezes, problemas que parecem ocorrer podem ser levados de volta às organizações e, então, não são mais problemas para a teoria dos sistemas. 


\section{INCLUSÃO E EXCLUSÃO}

Edvaldo Moita - Vou apenas fazer uma observação, porque ela se conecta com a minha pergunta com bastante clareza. Você publicou recentemente no Brasil um artigo ${ }^{8}$ que fornece uma contribuição útil à teoria dos sistemas, mostrando as transições de sistemas funcionais para interações e organizações e assim por diante. Você trabalha com a distinção "inclusão e exclusão" de uma maneira não-binária. Então, como você usa essa distinção em sua pesquisa? Essa seria a primeira pergunta. A segunda pergunta é: ao aplicar essa distinção em organizações e interações, você parece evitar a discussão sobre inclusão e exclusão, que aparece nos últimos trabalhos de Luhmann, no nível da diferenciação funcional. Ele chega a afirmar que essa forma de inclusão e exclusão é um meta-código que vem antes do código dos sistemas funcionais. Você concorda com esse tipo de pressuposto? Ou você colocaria de forma diferente? Ou, talvez, você se ateria aos conceitos de inclusão e exclusão no nível operacional de organizações e interações?

Lucas Amato - E gostaria de acrescentar que algumas pessoas dizem que o Estado de bem-estar alemão na época de Luhmann era o que garantia a diferenciação funcional, porque garantia a inclusão. Então, a diferenciação funcional estava apenas descrevendo esse Estado alemão a partir da década de 1970 ou é algo que pode ser observado na sociedade moderna mundial, como Luhmann afirma que está descrevendo?

Alfons Bora - Não tenho tanta certeza sobre a estreita conexão entre diferenciação funcional e Estado de bem-estar, porque a diferenciação funcional é um processo que abrange séculos. Ele foi muito ambivalente ao definir um ponto no tempo em que a diferenciação funcional começa. Às vezes, ele inicia no Século XI... Então, seja como for, é um processo muito longo, uma mudança dos tempos medievais para os tempos modernos. De acordo com como eu entendo Luhmann, [a diferenciação funcional] está estritamente associada à sociedade moderna e ao processo de evolução da sociedade moderna.

O Estado de bem-estar social é um episódio da sociedade moderna, um episódio bastante recente, e não tenho certeza se ainda estamos no Estado de bem-estar social ou se estamos enfrentando algo diferente. Provavelmente é algo diferente. Portanto, não consigo ver facilmente uma conexão estreita entre os dois termos teóricos, eles coocorrem entre o período pós-guerra e talvez até 1989 ou algo parecido. Eu não sei. Não tenho

\footnotetext{
${ }^{8}$ BORA, Alfons. “Quem participa?” Reflexões sobre teoria da inclusão. Tradução de Edvaldo de A. P. Moita. Revista Brasileira de Sociologia do Direito, v. 6, n. 3, p. 3-29, set./dez. 2019.
} 
certeza. Eu não sou especialista em teoria do Estado de bem-estar. Eu tenho que ser muito cauteloso nesse momento.

A diferenciação funcional é muito mais fácil e, como eu entendo a teoria, não está necessariamente relacionada à distinção entre inclusão e exclusão. Trata-se de um nível diferente. Conheço a observação de Luhmann sobre o meta-código [inclusão/exclusão] e não tenho certeza se ela é mais do que uma observação. Não quero falar sobre o autor dessa grande teoria de tal maneira, isso não nos ajuda muito, mas acho que o ponto não está muito desenvolvido, não consigo encontrar um lugar sistemático para essa observação.

Existe, no entanto, um argumento semelhante sobre códigos secundários: a moral como código secundário. Isso é muito claro na teoria. Eles ajudam a programar a aplicação do código primário. A relação entre moral e direito: que direito você deve seguir? Então, você chega à teoria moral, à Filosofia, e isso serve para ajudá-lo a programar a aplicação dessa "primeira ordem", o código principal.

Contudo, meta-código... A inclusão/exclusão programa a aplicação de códigos? A inclusão nos ajuda a distinguir entre lícito e ilícito? Não, eu não diria isso. A inclusão em si é uma questão normativa e você pode preferir normativamente a inclusão à exclusão, mas não tenho certeza se essa é uma posição muito prudente. Existem muitas situações em que você prefere a exclusão à inclusão. Eu poderia facilmente dar exemplos: big data, vigilância. Queremos ser incluídos neste sistema de observação de câmeras aqui? Não tenho certeza. Há pessoas discutindo contra isso. Eles preferem ser excluídos. Tudo bem. Eu só quero dizer que é uma relação difícil. Não vejo que a distinção entre inclusão e exclusão funcione da mesma maneira que uma codificação secundária pela moral, por exemplo. "Meta-código" ou qualquer outra coisa, não me sinto confortável com isso, veja bem, é complicado. 
Meu próprio entendimento de inclusão e exclusão: essa é sempre uma pergunta muito boa e não é fácil de responder. Talvez eu comece com o comentário de que os dois termos, inclusão e exclusão, não estão relacionados, como pode parecer à primeira vista, como outras distinções binárias, como se um fosse o contrário do outro. Eu penso que não. Eu simplesmente não consigo ver isso. O que quero dizer é que a relação entre inclusão e exclusão não é trivial, não é uma distinção binária simples.

Vamos começar com a exclusão: como você pode entender a exclusão? Parece que é o lado negativo silencioso da inclusão. A inclusão deve ser comunicada: você não terá inclusão se não endereça pessoas. Eu endereço a você, e nós nos endereçamos um ao outro, e é assim que as pessoas são incluídas no sistema de interação. Não é uma pessoa que faz isso, é a interação, a comunicação, que faz. Portanto, a inclusão é bem definida, mas a quem excluímos? Contem-me. Excluímos Lucas [que acabou de sair]? Ou excluímos 22 milhões de paulistas? Vocês entendem meu ponto? É fácil definir um lado e é muito difícil definir o outro lado.

A próxima ideia é a de que "é um espaço não marcado", mas não tenho certeza. Não tenho certeza se podemos aplicar George Spencer Brown aqui, porque a exclusão não é não marcada. Existe uma expressão para isso: "espaço não marcado" (unmarked-space), de George Spencer Brown - vocês o conhecem -, sempre significa que você simplesmente não pode se expressar, é qualquer outra coisa. Mas "exclusão"... Existe um termo para isso.

Então, primeiro aspecto: a exclusão parece ser o lado negativo silencioso da inclusão. Silencioso, na medida em que, neste exato momento, excluímos 9 bilhões de pessoas, que não estão incluídas em nossa interação. Mas isso é um problema? Não, é claro que não, é uma vantagem. É uma grande vantagem que eles não estejam incluídos.

No entanto, essa não é a história toda, obviamente, porque há uma preocupação com a exclusão e isso a torna muito complicada. Onde a exclusão entra em jogo? Ela entra em jogo como uma reivindicação normativa e agora uma base negativa para uma 
reivindicação normativa positiva. "Nos sentimos excluídos, por favor, inclua-nos". Isso faz com que ela seja tão complicada. É uma negação explícita de uma determinada situação que justifica, bem, não apenas reivindicações normativas, mas, eu diria, mais proeminentemente, reivindicações políticas. "Dê-nos poder, não temos poder, dê-nos mais". Então, acho realmente difícil falar sobre a distinção e, de alguma forma, colocá-la em uma terminologia científica teórico-sistemática precisa.

Talvez tenha sido essa a razão oculta sobre a qual eu não refleti na época. Faz mais de 20 anos. Eu me concentrei na inclusão, a inclusão era o problema. Tivemos esses procedimentos participativos, alegando [interrupção por sirenes do lado de fora]... Essa foi uma especificidade do debate jurídico alemão no final da década de 1970. Eles começaram a incluir um público amplo em procedimentos administrativos legalmente organizados (procedimentos de licenciamento, procedimentos de vários tipos...) com argumentos normativos que provaram ser muito políticos no final. A justificativa era que a "juridificação" dos procedimentos teve efeitos políticos negativos: "Die politischen Kosten des Rechtsstaats" (Os custos políticos do Estado de Direito), um texto muito famoso, pequeno e influente de Fritz Scharpf.

Então, a conclusão na teoria jurídica e na dogmática foi: "inclua as pessoas, deixe-as participar e, então, os procedimentos serão mais valiosos, mais eficazes, menos dispendiosos, serão justificados, legítimos no final". Coisas assim. Do ponto de vista sociológico, perguntei-me: o que está acontecendo aqui? Como podemos descrever isso? E o termo que se encaixava na situação era inclusão (tornar endereços sociais, em um determinado contexto, endereçáveis, torná-los relevantes, dar-Ihes voz). Então, eu estava lidando com a inclusão e as consequências de uma inclusão ilimitada - esse era o problema na época -, para permitir que o público em geral, literalmente falando, todos, todo mundo em um determinado contexto social, participasse em procedimentos, para dar o direito de participar. É uma forma de inclusão que pode - não necessariamente, mas 
pode - causar problemas graves em determinadas circunstâncias, especialmente quando a situação é predefinida pelo direito.

O efeito da ampla inclusão foi que as pessoas iniciaram comunicações sobre a legislação: “Por que você aplica essa disposição, essa engenharia genética? É antiético, é contra Deus, é contra o direito natural, apenas esqueça isso!" Esse foi o tipo de comunicação com a qual a administração foi confrontada, e você pode facilmente imaginar o que aconteceu. Eles foram forçados a aplicar o direito. Não havia possibilidade de ser flexível nessa situação específica. Era uma disposição vinculante na Lei de Engenharia Genética: você deve licenciar se as condições forem cumpridas, se a ciência disser que está tudo bem, mais ou menos. O risco é baixo, então você tem que licenciar. Nesse ponto, uma comunicação que reivindica a construção de normas, a legislação, cria sérios problemas. Esse era o tipo de coisa que você poderia explicar com essa observação sociológica e com o termo Vollinklusion: inclusão total criando sérios problemas em determinadas circunstâncias. Resposta longa, pergunta curta. Desculpem-me.

Edvaldo Moita - Essa foi uma resposta muito boa. Ela apontou a ideia principal por trás do uso do conceito. E isso me leva à segunda pergunta: a relação entre inclusão e exclusão. Parece que você, como em seu texto [mencionado anteriormente], aponta duas coisas diferentes, dois níveis diferentes. Então, eu o traria de volta para confrontar Luhmann a esse respeito: se você vê um grande contingente de excluídos, por exemplo, todo mundo está, em tese, incluído na economia, mas se você não tem dinheiro, como pode operar em tal sistema social? Quando você tem essa exclusão em massa, pode esse é o ponto de Luhmann - unir os conceitos de exclusão e integração no sentido de que altos níveis de exclusão social criam alto nível de integração, mas o contrário não é verdadeiro, não há conversão. No Brasil, pode-se ver facilmente que os pobres, se não possuem documentação, não podem ser endereçados, por exemplo, não podem ser matriculados em escolas. Mesmo se forem a outras organizações, não poderão participar. Então, ele une os conceitos de integração e exclusão nesse sentido. Como você reage a isso? Você acha que não é um exemplo claro de como unir os conceitos, ou é confuso e não ajuda a entender esse tipo de fenômeno que abordamos geralmente como exclusão social ou exclusão em massa? 
Alfons Bora - Apenas posso continuar minha resposta anterior. Primeiro, gostaria de perguntar: onde está a exclusão? Na sua pergunta, você a trata como um fato objetivo, algo que podemos observar: "aí está". Eu não tenho tanta certeza. No seu exemplo, eles não têm documentos e, portanto, não podem ser registrados nas escolas. Quando se torna exclusão? Torna-se exclusão no momento em que é comunicado, quando eles reivindicam, quando alguém diz que "eles devem ser endereçados", "eles devem ter documentos", "eles devem ter os direitos". Tudo é sempre sobre direitos. Então, essa é minha primeira dificuldade com o exemplo. Acho realmente difícil falar sobre exclusão de uma maneira como falamos sobre famílias ou interações, como fatos objetivos dados que simplesmente podemos ver. Não tenho certeza, veja bem, não tenho respostas fixas e definidas. É um campo complicado, é muito complexo.

A relação entre integração e inclusão: aí eu seguiria Luhmann. Você pode definir a integração como quiser, mas talvez seja preferível entendê-la como um certo tipo de interrelação entre sistemas, interdependência, a quantidade de liberdade que eles oferecem um ao outro, graus de liberdade na operação sistêmica. Se o grau diminuir, haverá interdependência e isso significa integração no sentido de Luhmann. Talvez seja a razão pela qual ele diz: "não há sociedade que não esteja integrada"; "toda e qualquer sociedade necessariamente está sempre integrada, sempre tem interdependências". Como seria possível não ter interdependências? Qualquer que seja o tipo, existem interdependências entre as pessoas pobres que não possuem documentos e a administração, o judiciário e a economia. Claro, existem interrelações e talvez - esse é o ponto de Luhmann - essas pessoas estejam mais fortemente integradas em outras partes da sociedade, porque elas têm todos esses problemas e conflitos. Os conflitos são os sistemas sociais mais estáveis, não se esqueçam. Os conflitos são sistemas sociais muito fortes e tendem a persistir, a sobreviver, e é exatamente isso que temos aqui: uma forte integração em que as pessoas poderiam alegar que deveriam ser mais incluídas. 
Então, novamente, para mim, é realmente difícil distinguir, separar os níveis do argumento. As coisas estão de alguma forma interrelacionadas, mas não é fácil descrever altos graus de integração em pontos em que semânticas de exclusão e demandas por mais inclusão podem surgir. Mas, novamente, é difícil dizer. Como medimos a integração? 0 ponto anterior: como a medimos? Você pode me dar os métodos? É difícil. Acho que não é por acaso que Luhmann sempre tocou no assunto, e não há uma solução elaborada para isso, e estou muito curioso para saber como vocês conseguirão resolver o problema.

\section{POLÍTICA E CIÊNCIA}

Henrique Carvalho - Minhas perguntas estão conectadas com outras já feitas. Recentemente, notamos uma série de eventos em todo o mundo, que, em certa medida, desafiam o paradigma posterior à Segunda Guerra Mundial, isto é, a construção de direitos humanos em bases sólidas, destinados a impedir o crescimento de problemas como, por exemplo, os grupos racistas nos EUA, o movimento "neonazista" na Alemanha e também as questões relacionadas à migração em diferentes regiões. Nos últimos anos, esses tópicos tiveram uma parte muito significativa das discussões na mídia e na política. Então, esse contexto traz de volta aos holofotes discussões antigas também nas Ciências Sociais, e aqui está a conexão com as teorias normativas. Portanto, aqui, relaciono-me explicitamente ao engajamento político de teorias normativas, por exemplo, a Teoria Crítica de Frankfurt e, como posso dizer, também os direitos humanos. Nesse contexto, gostaria de ouvir sobre a seguinte pergunta: qual papel essas abordagens teóricas desempenharam, ainda desempenham ou poderiam ter desempenhado em face de tal desafio?

Alfons Bora - Posso começar com Max Weber novamente? Se vocês se lembram de Politik als Beruf e Wissenschaft als Beruf [Política como Vocação, Ciência como Vocação], esses são os princípios básicos, e eu não consigo lembrar sua expressão literalmente, mas ele diz: "quando a política é considerada, todos devem seguir sua própria estrela." A ciência não tem acesso à definição de fins, a ciência está lá, ela depende muito de verificar os meios. Dadas as finalidades, a ciência fornece a você escrutínio e experiência para verificar os meios, e acho difícil ir além desse insight. Para mim, isso ainda é fundamental, embora possamos chegar a algumas melhorias, no que diz respeito à teoria dos sistemas. 
Agora, os exemplos que você mencionou. Eles são obviamente relevantes, são muito preocupantes, mas onde eles acontecem? É a política, o sistema político da sociedade mundial, eu diria, que está atualmente mudando de maneira dramática, ou seja, de uma maneira que o populismo - mais até do que os aspectos de direita - ganha uma relevância dramática. O populismo, eu acho, é uma das questões centrais. Ele anula o antigo elo entre política e ciência.

A ciência aconselha a política para melhorá-la. Isso é realmente uma defesa contra ataques populistas, com um entendimento errado do relativismo e do construtivismo. Isso é muito interessante, eles fazem uso de um construtivismo mal entendido, principalmente alegando que não há verdade, o que nenhum construtivista jamais poderia ter reivindicado, nem Niklas Luhmann, nem Rescher, nem ninguém mais. Não, isso é estúpido, é um absurdo, mas é extremamente eficaz no sistema político.

Então, há mudanças dramáticas, e qual poderia ser o papel da ciência em geral, e da Sociologia em particular, e especialmente na teoria dos sistemas? Antes de tudo, seguirei Weber e direi: "envolva-se na política, levante-se e faça seu papel de endereço político, inclua-se, não se sinta excluído pelo populismo". Isso é um inferno do problema, é realmente complicado. A teoria dos sistemas novamente pode ajudar a entender o que está acontecendo. Pode ser capaz de explicar o populismo. Não sei, não tenho lidado com essas questões, mas esse será o papel da ciência: tentar entender como os mecanismos são construídos e, a partir disso, talvez você possa voltar à política e tentar dar conselhos.

Em um campo muito diferente, não tão dramático quanto o da sua pergunta, foi o que fiz com minha pesquisa sobre participação. O livro sobre procedimentos participativos termina com política jurídica. Fiz sugestões para a alteração da Lei de Engenharia Genética, da Lei de Procedimentos de Administração Pública, coisas assim. Isso é possível, é claro. Se o fim estiver definido, se o objetivo for melhorar seu procedimento, tente evitar os impasses que ocorreram no procedimento antigo, onde as pessoas se sentiam muito 
desconfortáveis, as bases de legitimação eram muito fracas e assim por diante. Se esse é o problema, posso dizer como melhorar esse procedimento, mas não pela inclusão, pela inclusão de todos, em geral. Eu posso explicar por que isso não funcionou.

Sem ser capaz de Ihe dar uma resposta específica, eu afirmaria em geral que, também com relação aos problemas dramáticos e globais que você abordou, a Sociologia como disciplina e a teoria dos sistemas como uma teoria específica devem ser capazes de dar algumas respostas, não como [respostas] normativas - dizendo às pessoas o que é certo e o que não é certo -, mas como uma tentativa de dar conselhos cientificamente sólidos e embasados.

\section{SOCIOLOGIA DO DIREITO, SOCIÓLOGOS E JURISTAS}

Henrique Carvalho - Estou avançando para minha segunda pergunta, que se conecta à primeira de Gabriel, sobre sua biografia e sua experiência como professor. Lembro-me de um dos seus seminários sobre Sociologia do Direito, em que, ao reconstruir as raízes históricas da disciplina, você abordou uma singularidade, a saber: a Sociologia do Direito é um ramo da Sociologia composto principalmente por juristas. Essa afirmação não coincide apenas com o perfil deste Ciclo de Seminários Internacionais, realizado em uma Faculdade de Direito, organizado e visitado principalmente por juristas. Isso, com o devido respeito, liga-se também, em certa medida, à sua carreira, já que os seus estudos de graduação foram em Direito e, posteriormente, direcionados ao caminho da Sociologia. Quais fatores contribuíram e contribuem para esse caráter da Sociologia do Direito? Além disso, como você compararia o caminho de um jurista que ensina em uma Faculdade de Sociologia e um jurista que ensina Sociologia do Direito em uma Faculdade de Direito?

Alfons Bora - Falando sobre a Alemanha, uma pessoa que é apenas jurista não será capaz de sobreviver em uma Faculdade de Sociologia. Você precisa de ambos, nesse caso, precisa de alguma qualificação sociológica. No entanto, há alguns casos, como o meu próprio caso - e acho que existem muito poucos semelhantes, como Pierre Guibentif ou Doris Schweitzer, por exemplo -, em que a qualificação como advogado oferece uma forte vantagem nos departamentos sociológicos. É muito difuso, não é explícito, você não pode explicar isso, mas está lá, e isso tem a ver com o respeito geral à profissão. Tem vantagens, 
sim, nessa combinação, mas não será possível fazer carreira como sociólogo com apenas uma qualificação em Direito. De modo geral, como nos casos de vocês aqui, sempre há algum tipo de Sociologia e uma dissertação sociológica.

Sobre sua primeira pergunta, tentarei falar sobre isso em minha palestra, que tem a ver com Sociologia, a narrativa comum, a narrativa generalizada e amplamente aceita no campo, em toda a Sociologia do Direito é que os advogados não veem as tremendas vantagens da Sociologia, eles apenas negligenciam. "Sociologia ante portas" e os juristas não as abrem. Soziologie vor den Toren der Jurisprudenz, um livro muito famoso, de Rüdiger Lautmann, na década de 1970. Essa é a metáfora do entendimento comum, e eu diria que esse entendimento comum é profundamente errado, é um mal-entendido. Não é a única, mas uma das principais causas da fraqueza da Sociologia do Direito reside na Sociologia, notadamente no fato de que a Sociologia não está interessada em Direito, não está interessada em muitos campos pequenos. Temos uma Sociologia da Economia? Não tenho certeza. Temos atualmente uma Sociologia da Religião, uma teoria sociológica real? Eu não tenho tanta certeza.

Então, eu tentaria argumentar mais detalhadamente que existem fraquezas na Sociologia intimamente relacionadas à sua história, fraquezas que, como um efeito, levam à estranha situação, que você descreveu na sua pergunta, de que a Sociologia do Direito é representada principalmente por não-sociólogos, por sociólogos leigos... Não, desculpemme, isso foi uma piada. Existem muitos excelentes sociólogos do direito nas Faculdades de Direito. A fraqueza vem da teoria sociológica.

Agora sou provocador em um sentido muito forte: [a fraqueza] vem da teoria dos sistemas, do entendimento particular da teoria dos sistemas da relação entre ciência e prática, da hipotermia da teoria dos sistemas, como eu digo, com relação ao ambiente social da ciência. Ela vem de, como André Kieserling explicitamente chama, um gradiente pressuposto entre a ciência reflexiva da Sociologia ser capaz de explicar tudo e dizer o que 
você realmente está fazendo e os campos temáticos estarem envolvidos na observação de primeira ordem e sem saber o que fazem. Não há lugar para essa relação que eu chamaria de responsividade, ou seja, para uma teoria sociológica que, como uma teoria abrangente e complexa com altas aspirações, encontre um conceito para descrever e integrar essa relação de responsividade. Essa será a minha resposta mais longa e também está em um $\operatorname{artigo}^{9}$.

\section{JUSTIÇA E PRINCÍPIOS}

Artur Stamford da Silva - Para juntarmos todas as perguntas, um amigo, Marcelo Neves, disse-me que você é um especialista nos livros de Luhmann sobre o sistema jurídico. Então, pergunto: quais elementos desses livros você usa para falar sobre a justiça e os problemas latino-americanos? Luhmann diz que o direito não precisa de justiça, tem que abandonar a ideia de justiça...

Alfons Bora - Não, não seria uma boa ideia, falando de uma perspectiva sociológica, porque todos os sistemas precisam de fórmulas de contingência, semânticas que os ajudem a lidar com ambiguidades, em pontos onde a aplicação do código binário não é muito clara. Existem duas possibilidades igualmente lógicas ou convincentes e, então, o que você faz? O que os juízes costumam fazer? Eles balanceiam seus argumentos. Este é o ponto em que nossa fórmula de contingência e instrumentos semelhantes, princípios, por exemplo, são úteis. Os princípios talvez sejam ainda mais importantes do que a fórmula de contingência da justiça, entrando em cena, para ajudar a comunicar uma solução

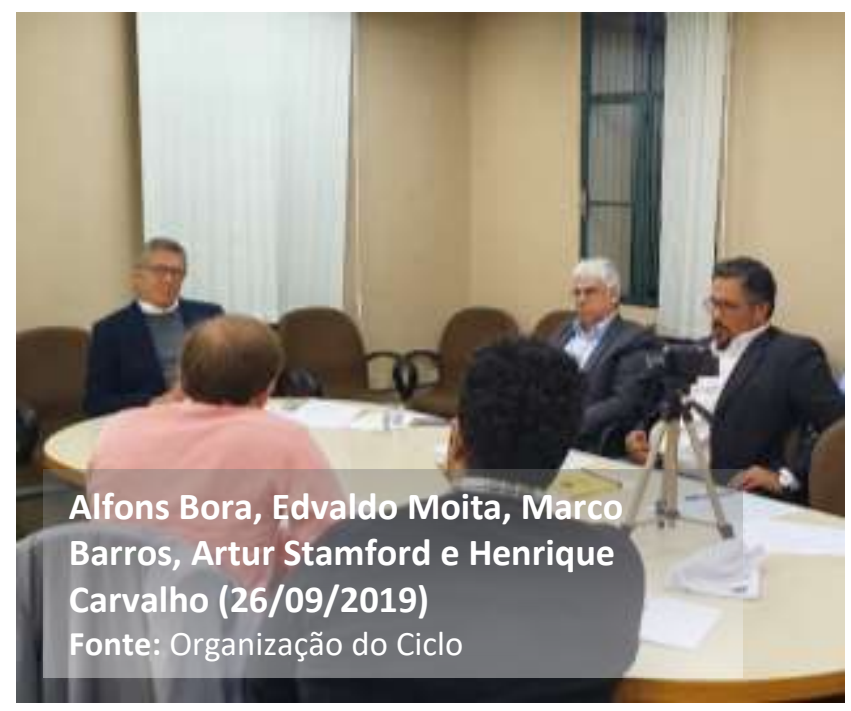

${ }^{9}$ BORA, Alfons. Sociology of law in Germany: reflection and practice. Journal of Law and Society, v. 43, n. 4, p. 619646, 2016. 
específica em uma determinada situação, ao ocultar de alguma forma a ambiguidade. Como os princípios funcionam? Os princípios trabalham com o jogo da regra e da exceção. “De um modo geral, somos a favor de ..., mas agora, neste caso, isso é completamente diferente." Isso é o princípio. Os princípios permitem não aplicar uma regra, eles têm a não aplicação em si mesmos. Então, minha resposta é: todos os sistemas precisam desses tipos de mecanismos, como o direito, é claro.

Muito obrigado por suas perguntas muito interessantes. 